\title{
De rol van de public controller
}

\section{Rick Anderson}

SAMENVATTING De public controller wordt in Nederland een steeds grotere rol en verantwoordelijkheid toegekend. Werd deze functionaris vijftien jaar geleden nog geassocieerd met de financiële bedrijfsvoering, tegenwoordig wordt de public controller binnen overheidsorganisaties verantwoordelijk gehouden voor de strategiebepaling, de risicobeheersing en zelfs het oplossen van maatschappelijke vraagstukken waar een overheidsorganisatie zich voor gesteld ziet. Dit artikel gaat in op de wenselijkheid, maar ook op het gevaar van deze functieverbreding. Het artikel baseert zich naast een literatuurstudie op een serie interviews en op een casestudie die in 2006 is verricht.

\section{RELEVANTIE VOOR DE PRAKTIJK Het artikel wijst op een discrepantie die is ontstaan} tussen de rol die sommige auteurs de public controller toekennen en de rol die de controller in de praktijk wordt toegedicht. Tevens wijst het artikel op het gevaar van de functieverbreding die door sommige auteurs wordt voorgestaan.

\section{Inleiding}

De taken en verantwoordelijkheden van publieke en private controllers zijn de laatste jaren veelvuldig object van onderzoek geweest (Verstegen en De Loo, 2007; Van der Meer, 2005). Daarbij valt op, dat de private controller steeds meer gezien wordt als ondersteuner, terwijl publieke controllers tegenwoordig geacht worden maatschappelijke doelen te definiëren en zich daar ook verantwoordelijk voor te voelen (vgl. Volberda, 2008; Minderman, 2008).

In dit artikel wordt gepoogd een antwoord te geven op de volgende vragen: welke rol zou de public controller in de praktijk van het openbaar bestuur moeten spelen, welke rol speelt hij feitelijk en welke factoren zijn bepalend voor de rolvervulling van de public controller?

Het artikel gaat aan de hand van een korte literatuurstudie eerst in op de ontwikkeling van de rol van de public controller. Vervolgens zal een reflectie vanuit de controllerspraktijk op deze ontwikkeling worden weergegeven.
Hiertoe zijn bij 32 controllers en managers binnen het openbaar bestuur interviews afgenomen. Daarbij stonden de vragen centraal welke rol de public controller zou moeten vervullen en welke rol hij in de praktijk feitelijk vervult. Aan de hand van deze reflectie wordt vervolgens een kader gepresenteerd waarbinnen de rol van de public controller gepositioneerd kan worden. Een samenvatting van een casestudie dient ter illustratie van dit kader. Het artikel sluit af met enkele conclusies en overwegingen.

\section{Ontwikkelingen binnen de controllersfunctie}

Hoewel de functie van controller verschillend wordt gedefinieerd en in de praktijk verschillende vormen aanneemt, wordt de controller doorgaans gezien als de management accountant (Anderson, 2006). Management accounting kent veelal een interne oriëntatie, waar financial accounting (externe verslaggeving) eerder een externe oriëntatie kent. Dit laatste werkveld wordt in Nederland veelal vervuld door accountants (vgl. Bovenkamp en Berkien, 1996, pp. 74-75). Een en ander is door Arentsen als volgt verwoord: 'Men zou kunnen zeggen dat management accounting de kernactiviteit is van de controllersfunctie. Financial accounting betreft de financiële administratie en de daaraan verbonden externe verslaglegging' (Faber, 1988, verslag lezing Arentsen, p. 35). Tot het takenpakket van de controller kunnen transactieverwerking, planning en control en beslissingsondersteuning gerekend worden (Van Helden, 1998, p. 10; Rosenberg en Tomkins, 1982; Anderson, 2006; San Miguel en Govindarajan, 1984; Faber, 1988, p. 78). Van oorspong was de functie van de public controller naar het evenbeeld van zijn private collega opgezet (Anderson, 2006).

Binnen het vakgebied van publieke en private controllers hebben zich de laatste jaren enkele verschuivingen voorgedaan waar het de rolvervulling van controllers betreft. Daarbij is het opvallend, dat de rol van de private controller zich in de literatuur anders ontwikkelt dan die van de public controller. De private controller wordt steeds vaker als ondersteuner gepositioneerd, terwijl de public 
controller juist een meer leidende rol krijgt toebedeeld (Otley, 1994, p. 297; Kaplan, 1995, p. 12).

Zo wordt gesteld dat private controllers ter ondersteuning van het management betrokken zijn bij het vormgeven en uitvoeren van management control (Verstegen en De Loo, 2007; Anthony en Young, 2004; Vaassen, 2002). Het gaat daarbij om de ontwikkeling van informatiesystemen en het aanbrengen van samenhang tussen de verschillende controlsystemen. Als ondersteuner zal de controller tevens een innovatief vermogen moeten hebben: 'Sturen op innovatie-indicatoren, een balans aanbrengen tussen exploitatie en exploratie, ondersteunen van projectteams en faciliteren van kennisallianties en open innovatie' (Volberda, 2008). Hoewel men in het algemeen pleit voor een verzwaring van de rol van controllers, blijft men de controller als ondersteuner positioneren (Strikwerda, 2008; Van der Meer, 2005; Swagerman, 2003). Ook blijft de beheersing van middelen een belangrijk onderdeel van zijn rol (ibid). Zo ziet Bossert in de controller de functionaris die ten behoeve van het management de financieel-economische besturing van de organisatie dient te bewaken (Bossert, 1993, p. 23). De controller heeft in deze visie een ondersteunende functie ten behoeve van het management, terwijl zijn primaire focus een financieel-economische is. Faber stelt in dit verband: 'Concluderend is de rol van de controller gericht op het genereren van managementinformatie ter ondersteuning van het management' (Faber, 1988, p. 79). De laatste jaren worden de public controllers echter steeds vaker als leidende actoren aangemerkt. Zo stelt Minderman dat de controller 'de kunst van het definiëren van maatschappelijke doelen en maatschappelijke producten dient te beheersen', waarmee deze auteur de controller een rol toekent in het formuleren van organisatiebrede en outputgerichte doelstellingen (Minderman, 2008, p. 62). Deze lijn wordt overigens niet altijd gevolgd. Zo stellen andere auteurs dat de public controller zich per definitie moet onthouden van het formuleren van doelstellingen, gelet op zijn controlerende taak (Glynn en Murphy, 1996; Masquefa, 2008; Otley, 2008; Newberry, 2002).

Vanuit de literatuur worden soms factoren aangedragen, die van invloed zijn op de rolvervulling van de controller. Zo lijkt de betekenis van niet-financiële informatie in het werk van een controller de laatste jaren te zijn toegenomen (Van Helden, 1998, p. 12). Auteurs zijn eenstemmig in de stelling dat financiële informatie over het algemeen een te zwaar accent heeft gekregen in het ontwerpen van controlsystemen (Otley, 1994, p. 295). De controller wordt nu meer geacht ook andere disciplines te betrekken in de producten en diensten die hij verzorgt. Hiermee zij niet gesteld, dat de controller zijn rol als bewaker van de financieel-economische rationaliteit zal opgeven, hoewel sommige auteurs hier wel voor waarschuwen (Traas, 1997, p. 43; Groot, 1997, p. 101).

\section{De interviews}

De interviews hebben als doel om te bezien welke rol de respondenten de public controller toekennen. Daarnaast beogen de interviews inzicht te geven in de rol die feitelijk wordt gespeeld. Tot slot kunnen met de interviews inductief verklaringen worden gevonden voor een mogelijke discrepantie tussen de normatieve rol en de feitelijke roluitoefening.

Aan 16 managers en 16 controllers zijn in bilaterale interviews een aantal vragen voorgelegd. De managers en controllers waren ten tijde van de interviews werkzaam binnen het openbaar bestuur en moesten minimaal in functieschaal 14 werkzaam zijn. Uit deze populatie zijn zij aselect getrokken. Alle respondenten zijn in twee rondes geïnterviewd.

In de eerste ronde werd gevraagd naar de rol die de controller zou moeten vervullen. Ook is gevraagd of de controller deze rol feitelijk vervult en welke factoren van invloed zijn op de daadwerkelijke vervulling van deze rol. De tweede vraag is dus in descriptieve zin gesteld. Door voor deze vraagstelling te opteren kan de discrepantie tussen de gewenste en de feitelijke rol inzichtelijk worden gemaakt en kunnen verklaringen voor deze discrepantie worden geduid.

De tweede ronde vormde een verdieping, waarbij werd doorgevraagd naar de factoren die in de eerste ronde aan de orde kwamen.

Aangezien de controllersfunctie onder verschillende benamingen schuil kan gaan (medewerker planning \& control, hoofd Bedrijfsbureau et cetera), is de respondenten eerst uitgelegd welke taken de controller vervult (transactieverwerking, planning- en controlfunctie, beslissingsondersteuning). Gelet op het onderscheid dat in de literatuur vaak gemaakt wordt tussen ondersteunend en leidend, is dit onderscheid voorgelegd tijdens de interviews. Om het onderscheid tussen ondersteunend en leidend duidelijk te maken, zijn twee uitersten benoemd. In het ene uiterste vervult de controller een geheel ondersteunende rol en heeft hij geen eigen verantwoordelijkheid voor een proces. In een ondersteunende rol worden dus niet zelfstandig doelstellingen geformuleerd en gerealiseerd ten aanzien van een bepaald proces. Uiteraard is de ondersteunende controller verantwoordelijk voor een adequate ondersteuning richting het management, maar deze verantwoordelijkheid is feitelijk afgeleid van de verantwoordelijkheid van de manager die ondersteund wordt. Het andere uiterste betreft de controller als leidende actor. Deze controller heeft wel zelfstandige verantwoordelijkheden (en dus ook bevoegdheden) ten aanzien van een bepaald proces. Zo worden vanuit een leidende rol doelstellingen ten aanzien van een proces zelfstandig geformuleerd en gerealiseerd. Tabel 1 toont de respons uit deze eerste ronde.

De meerderheid van de respondenten kent de controllers prescriptief een ondersteunende rol toe. In de praktijk 
Tabel 1 Respons eerste ronde interviews

\begin{tabular}{|c|c|c|c|c|}
\hline & \multicolumn{2}{|c|}{ Controllers } & \multicolumn{2}{|r|}{ Managers } \\
\hline Normatieve rol & & & & \\
\hline Ondersteunend & \multicolumn{2}{|l|}{15} & & 14 \\
\hline Leidend & \multicolumn{2}{|l|}{1} & & 2 \\
\hline \multicolumn{5}{|l|}{ Feitelijke rol } \\
\hline Ondersteunend & \multicolumn{2}{|l|}{4} & & 3 \\
\hline Leidend & \multicolumn{2}{|l|}{12} & & 13 \\
\hline Factoren van invloed & \begin{tabular}{|l} 
Positionering \\
Verwachting en behoefte manageme \\
Rol van andere actoren
\end{tabular} & $\begin{array}{r}(11 x) \\
(9 x) \\
(15 x)\end{array}$ & $\begin{array}{l}\text { Positionering } \\
\text { Behoefte management } \\
\text { Rol van andere actoren }\end{array}$ & $\begin{array}{l}(10 x) \\
(12 x) \\
(12 x)\end{array}$ \\
\hline
\end{tabular}

spelen de controllers echter merendeels een leidende rol. Onder de factoren die invloed uitoefenen op de rol die controllers daadwerkelijk spelen, worden door de controllers en managers de organisatorische positionering, de behoefte van het management en de rol van andere actoren opgevoerd. Met name de rol die andere actoren spelen (of juist niet spelen) kan er de oorzaak van zijn dat de controller zijn rol op een andere manier dan ondersteunend gaat vormgeven.

De organisatorische positionering betreft de vraag of de controller in de lijn of eerder stafachtig ${ }^{1}$ is ondergebracht. Normatief werd de controller eerder als staf- dan als lijnfunctionaris aangemerkt. Wel werd anngegeven dat controllers die in de lijn zijn ondergebracht, zich doorgaans teveel leidend opstellen.

Navraag leert, dat de behoefte van het management bepaald wordt door de manier waarop andere actoren hun rol vervullen. Als andere actoren worden in dit verband bestuurders, lijnmanagers, het hoofd Financiën en projectleiders genoemd. Naarmate deze actoren hun eigen rol minder invulling geven, neemt de kans toe dat de controller zijn rol gaat verbreden.

Verder gaven de respondenten aan, dat ook de oriëntatie van de controller een component is van de rol die hij vervult. De oriëntatie betreft het formuleren van doelstellingen. Zo kan de controller zich op de input (de middelen) richten en daartoe zijn doelstellingen formuleren, maar zich ook op doelstellingen ten aanzien van de output of de effecten van een bepaald proces concentreren. Normatief werd de controller gezien als een functionaris die zich zowel op de input als op de output moest richten. Ook hier is de daadwerkelijke oriëntatie van de controller mede afhankelijk van de oriëntatie van de andere actoren, aldus de respons.

De eerder gesignaleerde ontwikkelingen worden door de respondenten deels bevestigd. Zo neemt het belang van niet-financiële managementinformatie volgens de respondenten toe, hetgeen zich goed verhoudt tot de gedachte dat de controller zich ook op output moet oriënteren.
Aan de hand van de eerste interviewronde kan verondersteld worden, dat de controller normatief als ondersteunende staffunctionaris wordt aangemerkt, die zich op zowel input als output moet richten. In de praktijk speelt de controller echter een meer leidende rol. De manier waarop de rol daadwerkelijk wordt vormgegeven, hangt af van de positionering en de manier waarop andere actoren hun rol vervullen.

In de tweede interviewronde is eerst de vraag voorgelegd welke andere actoren prescriptief kunnen worden geplaatst tussen de twee uitersten 'ondersteunend' en 'leidend'. Verder is gevraagd welke organisatorische positionering de controller zou moeten hebben en of de controller zich zou moeten oriënteren op de inputfunctie of ook op de outputfunctie, en waar het accent zou moeten liggen. Deze vragen zijn ook voorgelegd ten aanzien van de andere actoren die naar aanleiding van de eerste vraag in beeld kwamen. Ook in deze ronde is gevraagd naar de feitelijke rolvervulling van de controller en de andere actoren. Tot slot is doorgevraagd naar de samenhang tussen rol, positionering, oriëntatie en rolvervulling door andere actoren.

Door de respondenten zijn de volgende actoren naast de controller opgevoerd: het hoofd Financiën, een projectleider, ambtelijk managers en politici. Deze actoren onderscheiden zich ten opzichte van elkaar en ten opzichte van de controller in hun rol (ondersteunend of leidinggevend), hun organisatorische positie (in de staf of in de lijn) en hun oriëntatie. De respons gaf aan, dat de controller een ondersteunende rol zou moeten vervullen vanuit de staf. Het hoofd Financiën werd gezien als een typische lijnfunctionaris met een leidende rol waar het de financiële bedrijfsvoering betreft. Een staffunctionaris met een meer leidende rol werd anngeduid als projectleider, terwijl ambtelijk managers zelf vanuit de lijn leiding moeten geven. Een bestuurder of politicus kent niet zozeer lijnverantwoordelijkheid, maar wel een leidinggevende functie. Deze typering werd door 15 controllers en 16 managers als zodanig herkend. Op het gebied van oriëntatie zag men het hoofd Financiën als iemand die primair, maar ook secundair 
gericht is op de middelenfuncties (input). De controller kent weliswaar een eerste oriëntatie op middelen, maar zal deze middelen wel moeten kunnen koppelen aan outputgerelateerde doelstellingen. Managers en projectleiders daarentegen werken andersom: vanuit outputgerelateerde doelstellingen hebben zij een secundaire oriëntatie op bijbehorende middelen. De bestuurder of politicus is bij uitstek iemand die het zich kan permitteren zich te beperken tot outputgerelateerde doelstellingen. Dit beeld werd door 13 controllers en 14 managers bevestigd. Twee controllers gaven aan, dat de controller zich feitelijk in het geheel niet met middelen moesten bezighouden. Eén manager stelde zich op het standpunt dat de controller zich juist enkel op de beheersing van middelen moest richten.

Ook de tweede ronde levert op, dat controllers in de praktijk een meer leidende rol vervullen dan wenselijk is. De vraag rees welke verklaringen hiervoor konden worden aangedragen en welke samenhang tussen deze verklaringen kon worden aangebracht. De ruimte die andere actoren laten liggen, bleek van groter belang te zijn dan de organisatorische positionering. Ook controllers die in de staf zijn gepositioneerd, zijn immers in staat een leidinggevende rol te vervullen als hun die ruimte wordt geboden. De oriëntatie van de controller bevindt zich in de praktijk te veel op de inputkant, aldus de respons, maar kent verder geen directe relatie met de rol die controllers vervullen: zowel leidende als ondersteunende controllers houden zich zowel met de input-als met de outputkant van het proces bezig.

\section{Het controllerskader}

De eerste ronde interviews leidt tot het inzicht, dat een verschil bestaat tussen de rol die controllers zouden moeten vervullen en de rol die zij feitelijk binnen hun organisatie vervullen. Daarnaast brengen de interviews in deze ronde een aantal verklaringen aan voor dit verschil. Zo worden in eerste instantie de positionering van de controller, de behoefte van het management en de rol die andere actoren vervullen als factoren aangedragen die de feitelijke rol van de controller beïnvloeden. In deze ronde is doorgevraagd naar deze factoren, hetgeen leidt tot de constatering dat de behoefte van het management bepaald wordt door de rol die andere actoren vervullen en dus niet als onafhankelijke factor gezien kan worden. Verder gaven de respondenten aan, dat de oriëntatie van de controller een belangrijk kenmerk is voor de rol die hij vervult, maar ook voor de rol die andere actoren vervullen.

De tweede interviewronde kan beschouwd worden als een verdieping van de eerste. Deze ronde beoogt niet zozeer nieuwe verklaringen te genereren, maar eerder de aangedragen verklaringen uit de eerste ronde meer te doorgronden. De factoren rol, positionering en oriëntatie van de controller zijn in deze tweede ronde wederom voorge- legd aan de respondenten. De respondenten moesten zich daarnaast uitlaten over de rol, positionering en oriëntatie van mogelijke andere actoren binnen de gemeentelijke organisatie.

Deze tweede ronde levert het inzicht op, dat de rol van de controller beïnvloed wordt door de organisatorische positionering, maar in sterkere mate door de manier waarop andere actoren hun rol vervullen, een constatering die eerder al door San Miguel en Govindarajan werd gedaan (San Miguel en Govindarajan, 1984).

De diverse factoren die tijdens de interviewsessie naar voren zijn gekomen, kunnen samen worden gebracht in een kader, dat als normatief kader kan dienen (zie ook tabel 2). Gelet op het belang dat aan de rolvervulling door andere actoren wordt gehecht, zal dit kader ook in moeten gaan op deze andere actoren. Dit kader kent geen universele geldigheid en beoogt dat ook niet: zij is aan de hand van een zeer beperkt aantal interviews inductief tot stand gekomen en ambieert enkel de gevonden verklaringen te duiden en mogelijkerwijs met elkaar in verband te brengen.

De controller zelf zou in eerste instantie een inputgerelateerde doelstelling moeten hebben. Zijn doelstelling betreft dan bijvoorbeeld het op peil krijgen van het eigen vermogen, het waarborgen van de rechtmatigheid van besteding of het voorkomen van budgetoverschrijdingen. Deze doelstelling zal de controller moeten koppelen aan andere doelstellingen binnen de organisatie. Het koppelen van doelstellingen is op zich niet specifiek voor een controller: ook andere actoren koppelen immers doelstellingen. Het specifieke van een controller ligt in het feit dat zijn eigen formele doelstelling inputgerelateerd is en dat hij vervolgens een koppeling maakt naar outputgerelateerde doelstellingen (vgl. Huys, 2005). Een controller die input niet aan output weet te koppelen en zich blijft concentreren op input, onderscheidt zich in zijn oriëntatie niet van een hoofd Financiën.

Verder zou de controller toe moeten zien op de bewaking van doelrealisatie en ook dit is niet specifiek voor een controller. Anderen dienen immers ook een zekere mate van doelrealisatie te waarborgen. Wat wel specifiek is, is dat de controller daarbij een ondersteunende rol vervult en geen leidende positie inneemt, zoals bestuurders, managers, hoofden Financiën en projectleiders. Dit houdt in, dat de controller geen zelfstandige processen onder zijn verantwoordelijkheid heeft en het formuleren van doelstellingen aan andere actoren moet overlaten, zie ook tabel 2.

De tabel maakt de diverse actoren en hun rol inzichtelijk. Tevens laat de tabel zien, dat het al dan niet hebben van budgetverantwoordelijkheid minder relevant is voor het al dan niet vervullen van een leidende rol. De vraag in hoeverre een actor zelfstandig doelstellingen kan formuleren en verantwoordelijk wordt gehouden voor een bepaald proces, oogt in dit verband relevanter. 
Tabel 2 De diverse actoren en hun rol

\begin{tabular}{|l|c|c|c|c|c|}
\hline & Bestuurder & Manager & Controller & Hoofd Financiën & Projectleider \\
\hline Primaire oriëntatie & Output & Output & Input & Input & Output \\
\hline Secundaire oriëntatie & Output & Input & Output & Input & Input \\
\hline Budgetverantwoordelijkheid in de lijn & Nee & $\mathrm{Ja}$ & Nee & $\mathrm{Ja}$ & $\mathrm{Nee}$ \\
\hline Zelfstandig formuleren van doelstellingen & $\mathrm{Ja}$ & $\mathrm{Ja}$ & $\mathrm{Nee}$ & $\mathrm{Ja}$ & $\mathrm{Ja}$ \\
\hline Verantwoordelijk voor proces & $\mathrm{Ja}$ & $\mathrm{Ja}$ & Nee & $\mathrm{Ja}$ & $\mathrm{Ja}$ \\
\hline Rol: leidend/ondersteunend & Leidend & Leidend & Ondersteunend & Leidend & Leidend \\
\hline
\end{tabular}

\section{De case}

Tabel 2 geeft aan, dat de controller een ondersteunende rol zou moeten vervullen, maar dat de controller de mogelijkheid heeft om zich meer leidend op te stellen als hij daartoe de ruimte krijgt. Deze leidende opstelling vertaalt zich dan met name in het zelfstandig formuleren van doelstellingen en het zich toe-eigenen van een bepaald proces.

Los van de respons is tevens een casestudie verricht naar de rol van de controller. De casestudie was een onderdeel van een dissertatieonderzoek naar de rol van controllers binnen het openbaar bestuur en dient in dit artikel ter illustratie van het beschreven kader (Anderson, 2006). Het object van de casestudie was het landgoed Profundum, een landgoed dat de gemeente Argus, met behulp van subsidies en in samenwerking met een private partij, beoogde te restaureren en te exploiteren. De private partij was Proton, een organisatie die trainingen verzorgde op het landgoed. De gemeente en Proton waren verenigd in de Stichting Exploitatie en hadden de beschikking over een projectbureau. Ten behoeve van de casestudie zijn de betrokken actoren geïnterviewd, documenten geanalyseerd, maar zijn ook raadsvergaderingen en managementteamvergaderingen bijgewoond. Daarnaast zijn de betreffende rechtszittingen bijgewoond en zijn bestanden van de computer van de controller geanalyseerd.

De case (zie kadertekst) laat zien hoe de controller een leidende rol weet te vervullen ten aanzien van een project, zonder dat hij daar de officiële bevoegdheid of verantwoordelijkheid toe had. Ten aanzien van het project formuleerde de controller niet alleen de doelstellingen, maar bepaalde hij ook de koers. Uiteindelijk liep dit project niet goed af, maar kon de controller niet worden aangesproken: formeel vervulde hij immers nog steeds een ondersteunende rol. Het gevolg was dan ook, dat een motie van wantrouwen tegen de wethouder werd aangenomen en dat het hoofd Economische Zaken zijn functie moest neerleggen: twee actoren die feitelijk geen invloed hadden uitgeoefend op de gang van zaken.

\section{Conclusies}

De casestudie is voor dit artikel enkel gebruikt als empirische illustratie. De casestudie illustreert het beeld dat ook uit de interviews naar voren komt: indien de controller te

\section{Case}

Het historisch verloop van de gebeurtenissen wordt niet in dit artikel opgenomen, maar kan als volgt worden samengevat. In mei 2002 verneemt de controller van de gemeente Argus dat er een overschrijding is van het gemeentelijk krediet op het landgoed Profundum van 3,6 miljoen euro. Nadere analyse wijst uit, dat de subsidies voor de restauratie van het landgoed bij de Stichting Exploitatie binnenkomen, terwijl de gemeente de voorfinanciering ter hand neemt. De controller formuleert na bilateraal overleg met twee portefeuillehouders een voorstel om de overschrijding zo veel mogelijk terug te dringen, hetgeen door het college wordt overgenomen. Een medewerker van de afdeling Economische Zaken fungeert tevens als penningmeester van de Stichting Exploitatie en wordt door de controller aangezet om het saldo van de stichting (twee miljoen euro) over te maken naar de gemeente. Om de resterende 1,6 miljoen euro voor de gemeente terug te halen, formuleert de controller het standpunt dat de gemeente de restauratie van het landgoed heeft gefinancierd en dus de enige actor is, die beslissingen kan nemen over het landgoed. Dit standpunt wordt overgenomen door het college en door het projectbureau, maar niet door de private partij, PROTON. Deze partij blijt in de Stichting Exploitatie gebruikmaken van haar vetorecht om de huurprijs vast te stellen, waarop het projectbureau op verzoek van de controller het landgoed van nieuwe sloten voorziet en het gebruik van het landgoed door PROTON onmogelijk maakt. Kort daarop gaat PROTON failliet en klaagt zij de gemeente aan voor de geleden schade. Daarnaast legt PROTON beslag op de banksaldi van de Stichting Exploitatie, mobiliseert het de pers en zet het een lobby in richting alle raadsfracties. Een raadsvoorstel van de hand van de controller om met een nieuwe stichting een doorstart te maken (zonder PROTON) wordt niet overgenomen in de raad, aangezien in het voorstel te weinig rekening wordt gehouden met de belangen van PROTON. Een onderzoek wordt ingesteld, wat er uiteindelijk toe leidt dat de wethouder Economische Zaken en het hoofd Economische Zaken hun functie neerleggen.

veel ruimte wordt gegeven, kan hij in sommige situaties de verantwoordelijkheid voor een bepaald proces naar zich toetrekken en zelfstandig besluiten nemen, zonder dat hij daarop kan worden aangesproken (vgl. San Miguel en Govindarajan, 1984). De functieverbreding van de public controller die door sommige auteurs wordt voorgestaan, wordt in de praktijk niet wenselijk geacht en kan zelfs tot een ondoorzichtige verantwoording leiden. 
De interviews geven niet alleen een illustratie van het werk van de controller in de praktijk, maar tevens een opmaat om tot een normatief kader te komen. Dit kader is slechts op een zeer beperkt aantal interviews gebaseerd en heeft enkel tot doel om de aangedragen factoren met elkaar in verband te brengen. Het kader laat wel zien, dat de rol van de controller niet los gezien kan worden van en deels bepaald wordt door de rol die andere actoren vervullen. Op het moment dat andere actoren minder 'rolvast' opereren, neemt het gevaar toe dat de controller zijn functie gaat verbreden. De controller wordt geacht een bijdrage aan de verbetering van doelmatigheid te leveren. Hij zal dat moeten doen door zijn primaire inputgerelateerde doelstelling te koppelen aan doelstellingen (van andere actoren) op het gebied van output en door de realisatie van doelstellingen te waarborgen. Hierbij vervult de controller een ondersteunende rol: hij is en blijft adviseur en geen eindverantwoordelijke functionaris (vgl. Anthony en Young, 2003, p. 394; Glynn en Murphy, 1996). De ogenschijnlijke contradictie, namelijk dat de controller een bijdrage dient te leveren aan de verbetering van doelmatigheid en dit niet vanuit een verantwoordelijke maar vanuit een ondersteunende rol dient te doen, is een specifiek kenmerk van de functie van controllers.

Het bieden van ondersteuning kan echter zeer uitdagend en inspirerend zijn. Deze ondersteuning betreft immers al lang niet meer het verzorgen van enkel financieel inzicht. Juist het concretiseren van politiek-bestuurlijke doelstellingen en het faciliteren daarvan, behoort tot de rol van de controller. Dat faciliteren kan zich tevens vertalen naar de ontwikkeling van een dynamisch controlsysteem. Dit systeem staat dan in het teken van het geven van betekenis aan (toekomstige) activiteiten in de organisatie(Vosselman, 2008, p. 168; vgl. Ter Bogt, 2003; Verbeeten, 2008). Ook kan de controller een taak hebben in het aanbrengen van samenhang tussen de diverse controlsystemen binnen de organisatie, een samenhang die niet altijd automatisch aanwezig is (Widener, 2007). Waar het de inrichting van processen en budgetsystemen betreft, kan de controller een ondersteunende, maar zeer waardevolle rol spelen. Door processen te (her)ontwerpen en te voorzien van een adequate budgetteringssystematiek, kan de controller immers conflicterende belangen weer laten congrueren en voldoende betrokkenheid waarborgen (Anderson, 2006; Rajan en Reichelstein, 2006; Larcker e.a., 2007; Otley, 2008). Ondersteuning kan zich ook vertalen naar het zoeken en bewaken van de juiste balans tussen efficiency en vernieuwing en het faciliteren van netwerken en kennisallianties (Meier en O'Toole, 2001; Volberda, 2008; Newberry, 2002).

De grootste uitdaging van ondersteuning ligt echter in het gegeven dat deze ondersteuning zich richt op verschillende actoren die soms conflicterende doelstellingen hebben.

Dr. R.J. Anderson is als lector Controlling verbonden aan de Hogeschool INHOLLAND.

\section{Literatuur}

Anderson, R.J. (2006), Tussen schakelen en switchen, een dissertatie onderzoek naar de functie van controllers binnen Nederlandse gemeenten, Enschede: Gildeprint.

anthony, R.N. en D.W. Young (2004), Management control in non-profit organizations, Boston: McGraw-Hill.

- Bogt, H.J. ter (2003), Performance evaluation styles in governmental organizations: How do professional managers facilitate politicians' work?, Management Accounting Research, vol. 14, no. 4, December, pp. 311-332.

- Bossert, J. (1993), De organisatie van besturingsprocessen, Vrije Universiteit, Amsterdam.

- Bouma, J.L. (1990), Ontwikkelingen in het management accounting-onderzoek, Maandblad voor Accountancy en Bedrijfseconomie, vol. 64, no. 11, november, pp. 478-490.

- Bovenkamp, A.P. van de, en J.A.M Berkien (1996), Cooper: management-accountant terug naar af..., Tijdschrift Financieel Management, vol. 16, no. 5, september/oktober, pp. 69-75.

- Cooper, R. (1996), De veranderende praktijk van management accounting I, Tijdschrift Financieel Management, vol. 16, no. 3, pp. 9-19. - Faber, J. (1988), De inhoud en organisatie van de controllersfunctie, Tijdschrift Financieel Management, vol. 8, no. 3, pp. 35.

- Glynn, J.J., en M.P. Murphy (1996), Public management. Failing accountabilities and failing performance review, The International Journal of Public Sector Management, vol. 9, no. 5/6, pp. 125-137.

- Groot, T.L.C.M. (1997), De ontwikkeling van management accounting theorie en praktijk, Maandblad voor Accountancy en Bedrijfseconomie, vol. 71, no. 3, maart, pp. 96-104. - Helden, G.J. (1998), Veranderingen in de functie en rol van de controller, paper, RUG, Groningen.
- Huys, G. (2005), De functie van de controller, bijdrage TCG Congres, 2005, Amersfoort.

- Kaplan, R.S. (1995), De nieuwe rol van de controller, Tijdschrift voor Financieel

Management, vol. 15, no. 3, pp. 10-23.

- Larcker, D.F., S.A. Richardson en I. Tuna (2007), Corporate governance, accounting outcomes, and organizational performance, The Accounting Review, vol. 82, no. 4, pp. 963-1008.

- Masquefa, B. (2008), Top management adoption of a locally driven performance measurement and evaluation system, Management Accounting Research, vol. 19, no. 2, June, pp. 182-207.

- Meer, E.H. van der (2005), Control als recept voor succesvol ondernemen, INHOLLAND, Alkmaar.

- Meier, K.J., en L.J. O'Toole Jr. (2001), Managerial strategies and behavior in networks, Journal of Public Administration Research and Theory, vol. 11, July, pp. 271-294. 
- Merchant, K.A., en D.T. Otley (2007), A review of the literature on control and accountability, in: C.S. Chapman, A.G. Hopwood en M.D Shields, Handbook of management accounting research, Oxford/Amsterdam: Elsevier Press, vol. 2, pp. 785-802.

- Minderman, G. (2008), Legitimatie \& Verankering, Amsterdam: VU Public Controlling reeks, no. 1.

- Newberry, S. (2002), Intended or unintended consequences? Resource erosion in New Zealand's government departments, Financial Accountability \& Management, vol. 18 , no. 4, November, pp. 309-330.

- Otley, D. (1999), Performance management: A framework for management control systems research, Management Accounting Research, vol. 10, no. 4, December, pp. 363-382.

- Otley, D. (2008), Did Kaplan and Johnson get it right?, Accounting, Auditing \& Accountability Journal, vol. 21, no. 2, pp. 229-239.

- Otley, D. (1994), Management control in contemporary organizations, Management Accounting Research, vol. 5, no. 3/4, September, pp. 289-299.

- Rajan, M.V. en S. Reichelstein (2006), Subjective performance indicators and discretionary bonus pools, Journal of Accounting Research, vol. 44, no. 3, June, pp. 585-618.
- Rosenberg, D. en C. Tomkins (1982), A work role perspective of accountants in local government service departments, Accounting, Organizations and Society, vol. 7, no. 2, April, pp. 123-137.

- San Miguel, J.G. en V. Govindarajan (1984), The contingent relationship between the controller and internal audit functions in large organizations, Accounting, Organizations and Society, vol. 9, no. 2, April, pp. 179-188.

- Strikwerda, H. (2008), De plaats en de rol van de accountant in de 21e eeuw, Maandblad voor Accountancy en Bedrijfseconomie, vol. 82 . no. 3, maart, pp. 77-88.

- Swagerman, D.M. (2003), Op weg naar herstel van vertrouwen: wat kan de controller daaraan bijdragen?, Oratie, Rijksuniversiteit Groningen.

- Traas, L. (1997), Management accountants/ controllers onder de maat?, Tijdschrift Financieel Management, vol. 17, no. 4, juli/augustus, pp. 43-45.

- Vaassen, E.H.J. (2002), Accounting Information Systems: A Managerial Approach, Chichester: John Wiley \& Sons.

- Verbeeten, F.H.M. (2008), Performance management practices in public sector organizations: Impact on performance, Accounting, Auditing \& Accountability Journal, vol. 21, no. 3, pp. 427-454.

- Verstegen, B. en I. de Loo (2007), Gedragspatronen van Nederlandse controllers: een analyse aan de hand van interpretatief interactionisme, Maandblad voor Accountancy en Bedrijfseconomie, vol. 81, no. 1 / 2, januari/ februari, 19-27.

- Volberda, H. (2008), De controller als aandrijver of remmer van innovatie?, Maandblad voor Accountancy en Bedrijfseconomie, vol. 82, no. 4, april, pp. 142-144.

- Vosselman, E.G.J. (1999), Management accounting onderzoek en controllership, Maandblad voor Accountancy en Bedrijfseconomie, vol. 73, no. 3, maart, pp. 95-105.

- Vosselman, E.G.J. (2008), Accounting, instrumentalisme en het organisatorisch samenwerkingsverband, Maandblad voor Accountancy en Bedriffseconomie, vol. 82, no. 4, april, pp. 161-169.

- Widener, S.K. (2007), An empirical analysis of the levers of control framework, Accounting, Organizations and Society, vol. 32, no. 7/8, October, pp. 757-788.

\section{Noot}

1. Daarbij is lijnverantwoordelijkheid gedefinieerd als budgetverantwoordelijkheid. Staffunctionarissen kennen volgens deze definitie geen budgetverantwoordelijkheid. 